\title{
Very low hepatitis $C$ viral loads in treatment-naïve persons: do they compromise hepatitis $C$ virus antigen testing?
}

\author{
Barbara Bertisch $^{1}{ }^{*}$, Matteo Brezzi ${ }^{1}{ }_{\dagger} \dagger$, Francesco Negro ${ }^{2}$, Beat Müllhaupt ${ }^{3}$, Cornelia Ottiger ${ }^{4}$, Patrizia \\ Künzler-Heule ${ }^{5}$, Patrick Schmid ${ }^{6}$, Fabio Giudici ${ }^{7},{\text { Olivier } \text { Clerc }^{8} \text {, Alberto Moriggia }}^{9}$, Maroussia Roelens ${ }^{1}$, \\ Francesco Marinucci ${ }^{10}$, Cinzia Zehnder ${ }^{11}$, Darius Moradpour ${ }^{12}$, Olivia Keiser ${ }^{1}$, for the Swiss Hepatitis C Cohort
} Study

* equal contribution

† Deceased

1 Institute of Global Health, University of Geneva, Geneva, Switzerland. Barbara.bertisch-moellenhoff@unige.ch; Tel: 0041223790869

2 Divisions of Gastroenterology and Hepatology and of Clinical Pathology, University Hospitals, Geneva, Switzerland.

3 Swiss Hepato-Pancreato-Biliary Center and Department of Gastroenterology and Hepatology, University Hospital, Zürich, Switzerland.

4 Department of Laboratory Medicine, Cantonal Hospital Aarau, Aarau, Switzerland.

5 Division of Gastroenterology and Hepatology, Cantonal Hospital St Gallen, St Gallen, Switzerland.

6 Division of Infectious Diseases and Hospital Epidemiology, Cantonal Hospital St. Gallen, St. Gallen.

7 Institute of Social and Preventive Medicine, University of Bern, Bern, Switzerland.

8 Department of Internal Medicine and Infectious Diseases, Pourtalès Hospital, Neuchâtel, Switzerland.

9 Fondazione Epatocentro Ticino, Lugano, Switzerland.

10 Foundation for Innovative New Diagnostics (FIND), Geneva, Switzerland

11 SYNLAB Suisse SA, Bioggio, Switzerland.

12 Division of Gastroenterology and Hepatology, University Hospital Lausanne, Lausanne, Switzerland.

Corresponding author:

Barbara Bertisch, Institute of Global Health, University of Geneva, 9 Chemin des Mines, 1202 Geneva. Tel: 0041223790869 or 00417884329 24, email: barbara.bertisch-moellenhoff@unige.ch

(C) The Author(s) 2019. Published by Oxford University Press for the Infectious Diseases Society of America. All rights reserved. For permissions, e-mail: journals.permissions@oup.com. 
Summary:

Among 2,533 chronically hepatitis C-infected, treatment-naive persons in the Swiss Hepatitis C Cohort Study, 133 persons (5,3\%) ever had a viral load $\leq 3,000 \mathrm{IU} / \mathrm{ml}$. Part of these showed favourable disease courses, but 24 persons, all immunosuppressed, had cirrhosis. 
Abstract:

\section{Background}

Hepatitis C virus (HCV) antigen testing is less expensive than quantitative RT-PCR but has lower sensitivity for very low viral loads (VLVL; HCV RNA $\leq 3,000 \mathrm{IU} / \mathrm{ml}$ ). Currently the benefits of antigen testing for screening are discussed, but data on prevalence and outcomes of persons with VLVL are scarce.

\section{Methods}

We assessed prevalence and predictors of VLVL by logistic regression in treatment-naïve participants in the Swiss Hepatitis C Cohort Study. We analyzed if the last viral load after VLVL was low, compared cirrhosis and mortality in persons with and without VLVL, and evaluated the number of samples with VLVL that were reactive by antigen testing.

\section{Results}

We included 2,533 treatment-naïve persons with available quantitative HCV RNA testing results. Overall, 133 persons (5.3\%) had a VLVL. Age $18-40$ years, female gender and HIV coinfection were associated with VLVL. Of 72 persons with a viral load available after VLVL, 14\% had a VLVL and $17 \%$ had spontaneous viral clearance. The prevalence and incidence of cirrhosis and mortality were comparable in persons with and without VLVL; all 24 persons with VLVL and cirrhosis had excessive alcohol consumption or immunosuppression. Overall 33\% of samples with VLVL were reactive by antigen testing.

\section{Conclusions}

The frequency of VLVL was low. Among the persons who would probably be missed by antigen screening, some had a favorable disease course, but some had immunosuppression and liver cirrhosis. The benefit of $\mathrm{HCV}$ antigen testing for screening may be limited by the risk of missing patients with severe liver disease. 
Keywords:

hepatitis C, very low viral load, antigen, screening, cirrhosis 


\section{Background}

Treatment-naïve persons with hepatitis C virus (HCV) infection usually have viral loads around $10^{5}-10^{6}$ $\mathrm{IU} / \mathrm{ml}$ [1-3]. Viral loads $<400,000-800,000 \mathrm{IU} / \mathrm{ml}$ have been referred to as "low viral loads" [4-7] and have been associated with higher proportions of spontaneous viral clearance $[7,8]$, slower liver disease progression [9-11], improved response to interferon-based treatment [4,6], and more successful treatment of liver cancer [12]. In contrast, other studies have found no association between low viral loads and liver disease progression $[2,13,14]$.

Viral loads $<600 \mathrm{IU} / \mathrm{ml}[1]$ and $<5,000 \mathrm{IU} / \mathrm{ml}[15]$ have been referred to as "very low viral loads" (VLVL). Recently, the frequency and prognostic value of VLVL have been discussed controversially in the context of HCV antigen testing $[16,17]$. HCV antigen testing can be a less expensive alternative to quantitative RT-PCR [14,16,18-21]. In resource-limited settings with high HCV prevalence, point-of-care antigen testing is discussed as a one-step procedure, without HCV antibody screening [21]. The sensitivity of HCV antigen testing to detect VLVL is low: in most studies, the only commercially available HCV antigen test had a detection limit of 3,000 IU/ml [17,22-27]; in a few studies the detection limit was 1,000 IU/ml [28-30].

Little is known about the prevalence of VLVL among treatment-naïve persons. A study on laboratory samples with first-time HCV antibody positivity found viral loads $\leq 3,000 \mathrm{IU} / \mathrm{ml}$ in $3 \%(6 / 221)$ [24]. A metaanalysis on viral loads in untreated persons had exclusion criteria such as viral loads $<2,000 \mathrm{IU} / \mathrm{ml}$ and genotypes other than one; the results are therefore not relevant in our context [31]. Other studies were limited to settings where the majority of persons were treatment-experienced $[1,15,29]$; results are therefore not applicable to screening, where persons are treatment-naïve. More data are needed to better estimate the probability of missing HCV-positive persons with a VLVL at the time of screening, and to obtain information on their disease course. We therefore assessed the prevalence of VLVL in treatment-naïve persons, compared the characteristics and outcomes of persons with and without VLVL and analyzed the number of VLVL detected by antigen testing. 


\section{Methods}

We considered all persons enrolled in the Swiss Hepatitis C Cohort Study (SCCS) until September 10, 2017. The SCCS is a multicentre cohort study with continuous enrolment of anti-HCV positive persons aged $>18$ years [32]. Study sites include five university hospitals, three additional large hospitals, and some affiliated centres. Enrolment started in the year 2000, and persons in any stage of disease are included. The standardized questionnaire includes data on demographic characteristics, HCV risk factors, genotype, HIV coinfection, organ transplantation and alcohol consumption. Clinical information is collected at enrolment and during yearly follow-up visits; at the same time plasma samples are collected and stored. The ethics committees of all eight participating hospitals granted ethical approval and all participants gave written informed consent.

To avoid any treatment effects, we excluded all participants who were treated before enrolment into the SCCS. For participants who started their HCV treatment in the SCCS, we only considered viral loads before treatment start. In treatment-naïve participants, we considered all viral loads. We defined a VLVL as HCV RNA $\leq 3,000 \mathrm{IU} / \mathrm{ml}$ because most studies on HCV antigen testing had used this detection limit $[17,22-27]$.

We performed five different analyses. First, we calculated the proportion of persons who ever had a VLVL among all persons with at least one available viral load. We evaluated if this proportion changed over time, considering the following time intervals after enrolment into the SCCS: $\geq 6$ months to $<3$ years, $\geq 3$ to $<5.5$ and $\geq 5.5$ to $<8$ years. We performed a chi-squared test for trend in proportions, and excluded the first six months from the analysis because spontaneous viral clearance is more frequent during this time period $[7,33,34]$. We compared the number of viral load tests in persons with and without VLVL. Since a VLVL may trigger more frequent testing, we compared the mean time between viral load tests before and after the first documented VLVL. We compared the proportion of people with a VLVL (among all patients with an available viral load) by type of quantitative RT-PCR assay used.

Second, we assessed possible predictors of VLVL. We used univariable and multivariable logistic regression and included the following explanatory variables at cohort enrolment: gender, age (18-40,>40 years old), HCV genotype (1, 2, 3, 4; other genotypes were very rare and set to missing), history of intravenous drug 
use (IVDU, yes/no), time elapsed between first documented HCV infection and enrolment ( $<2$ years, 2 to $<6,6-10$ and $>10$ years), alcohol consumption (no or light: $<20$ grams of alcohol per day; moderate: 20-40; excessive: >40; former: used to drink $>40$ grams of alcohol before enrolment), HIV coinfection, HBV coinfection, and presence of liver cirrhosis at enrolment.

Third, we compared the prevalence and incidence of liver cirrhosis and all-cause mortality in persons with and without VLVL. We used univariable and multivariable logistic regression for prevalent cirrhosis, and Cox regression for incident cirrhosis and mortality. We included the same covariates as in the analysis of predictors of VLVL, but excluded "presence of liver cirrhosis at enrolment". In persons with VLVL and cirrhosis, we extracted information from the patient charts on additional immunosuppressive conditions and treatments.

We used multiple imputation by chained equations (MICE package for R; Van Buuren \& GroothuisOudshoorn 2011 [35]) to impute missing values in the covariates. Because the quality of the imputation can be improved by adding variables outside the analysis [36], we included if HCV treatment was started within the SCCS, if spontaneous HCV clearance occurred, the SCCS center enrolling the participant, and the respective outcome variable. We ran the model on 20 imputed datasets for each analysis and used Rubin's rule to pool the estimates.

Fourth, we analyzed the viral load trajectories after VLVL in persons with at least one viral load available $\geq 6$ months after the first VLVL. Depending on the last viral load value (negative, $>0$ to $\leq 3,000 \mathrm{IU} / \mathrm{ml}$ or above), we classified the persons as "undetectable", "continuous VLVL" or "rebound after VLVL". We further classified persons with an undetectable last viral load as "confirmed spontaneous clearers" if they had two undetectable viral loads $\geq 6$ months apart, and otherwise as "possible spontaneous clearers" [7]. We repeated the analyses with a viral load detection limit of $1,000 \mathrm{IU} / \mathrm{ml}$ instead of $3,000 \mathrm{IU} / \mathrm{ml}$; for the fourth analysis, the sample size was too small.

Fifth, in all participants with a frozen plasma sample available at the time of the VLVL, we performed antigen testing. We analyzed the antigen test results separately for $V L V L \leq 3,000$ and $V L V L \leq 1,000 \mathrm{IU} / \mathrm{ml}$, and classified them as reactive $(>10 \mathrm{fmol} / \mathrm{l})$, borderline reactive $(3-10 \mathrm{fmol} / \mathrm{l})$ and negative $(<3 \mathrm{fmol} / \mathrm{l})$. 
As controls, we performed HCV antigen testing in 18 plasma samples with viral loads $>3,000-50,000$ $\mathrm{IU} / \mathrm{ml}$, and in two plasma samples with undetectable HCV RNA.

All the analyses were performed with R version 3.4.3 (R Core Team 2017, https://www.r-project.org). 


\section{Results}

We included 2,533 persons ( $46.8 \%$ of 5,409 persons enrolled in the SCCS) who had HCV viral loads measured in the absence of therapy or before treatment start (Figure 1 and Table 1). Overall, 5.3\% $(133 / 2,533)$ of persons ever had a VLVL (Figure 1, Table 1), and 26 persons had a VLVL at least twice. Acute HCV infection before documentation of VLVL was excluded in 125 of the 133 persons (94\%; HCV diagnosis $\geq 6$ months before VLVL), was unlikely in seven persons (5\%; probable HCV infection $\geq 5$ years before VLVL), and could not be excluded in one person (1\%; active IVDU with negative HCV test 1.5 years before VLVL).

The percentage of persons with a VLVL remained stable over time, ranging from 3.0 to $4.1 \%$ for the time intervals of 2.5 years (Table 1). Viral loads were measured more frequently in persons with than without a VLVL (mean number of measurements 4.2 vs. 2.3 , p-value $<0.001$ ); the time interval between measurements remained similar before and after a VLVL (mean of 671 days before and 723 days after a VLVL, $p=0.703$ ). For different quantitative RT-PCR assays, the proportion of people with a VLVL (among all persons with a detectable viral load) was similar.

Older age ( $>40$ years), male gender, and being HIV-negative were associated with a lower probability of a VLVL (adjusted odds ratios 1.79, 95\% Cl 1.77-2.73; 1.50, 95\% Cl 1.00-2.24; and 2.20, 95\% Cl 1.24-3.92), while HCV genotype, history of IVDU, time between documented HCV infection and cohort enrolment, alcohol consumption, HBV coinfection, and cirrhosis at enrolment were not. Results were similar in the univariable analysis and if missing explanatory values were imputed by multiple imputation (Table 2), except for gender that was no longer associated. Viral load levels before the VLVL were comparable for persons with and without subsequent spontaneous clearance (median 233,615 vs 117,253 IU/ml, p=0.91; $\mathrm{n}=35$ persons).

Among the 133 persons with a VLVL, 18\% (24 persons) had liver cirrhosis. Cirrhosis at enrolment, incident cirrhosis and mortality were similar in persons with and without VLVL (Table 3). All 24 persons with a VLVL and liver cirrhosis had at least one of the following conditions: HIV coinfection, organ transplantation, 
(history of) excessive alcohol consumption, immunosuppressive treatment, diabetes mellitus, active IVDU with opioids, biliary cirrhosis or hepatitis B/D virus coinfection.

Seventy-two of the 133 persons with a VLVL had at least one viral load available $\geq 6$ months after their first VLVL. Of these, $14 \%(10 / 72)$ had a VLVL as their last viral load, $17 \%(12 / 72)$ spontaneously cleared the virus (eight with confirmed, four with possible clearance), and $69.4 \%(50 / 72)$ had a last viral load $>3,000 \mathrm{IU} / \mathrm{ml}$. Four of the 72 persons, all with active IVDU, were probably reinfected after viral clearance; however a detailed sequence analysis was not available. Among the 24 persons with a VLVL and liver cirrhosis, 12 persons had at least one viral load available $\geq 6$ months after their first VLVL. Of these, $42 \%(5 / 12)$ spontaneously cleared the virus or had a VLVL as last result (four after stop of excessive alcohol use, one after steroid treatment); $58 \%(7 / 12)$ had a viral load $>3,000$ as last result (six being immunosuppressed, one with excessive alcohol consumption and hepatitis B/D virus coinfection).

When we repeated the analyses using $\leq 1,000 \mathrm{IU} / \mathrm{ml}$ to define a VLVL, results were similar. Overall $3.5 \%$ $(88 / 2,533)$ of the participants ever had a VLVL $\leq 1,000 \mathrm{IU} / \mathrm{ml}$, and the percentage of persons who ever had a $\mathrm{VLVL} \leq 1,000 \mathrm{IU} / \mathrm{ml}$ remained stable over time ( $2.1 \%$ to $2.8 \%$ across the three time intervals). Young age (1840 years), excessive alcohol consumption and absence of IVDU were associated with VLVL $\leq 1,000$ (adjusted odds ratios $2.15,95 \% \mathrm{Cl} 1.26-3.67 ; 1.92,95 \% \mathrm{Cl} 1.03-3.57$; and 1.94, 95\% $\mathrm{Cl} 1.10-3.42$ ), while the other covariates were not. In the univariable analysis, the covariates associated with VLVL $\leq 1,000$ were young age and excessive alcohol use (compared to no or light drinking). There were no differences between persons with and without a VLVL $\leq 1,000$ for prevalence of cirrhosis at enrolment, incidence of cirrhosis and mortality.

Among the 133 persons with a VLVL, 90 persons had the VLVL documented at the yearly SCCS visit and 43 during another visit when no plasma sample was stored. For one person, the frozen plasma sample was unavailable. For the remaining 89 persons, $\mathrm{HCV}$ antigen testing for $\mathrm{VLVL} \leq 3,000 \mathrm{IU} / \mathrm{ml}$ was reactive in $24 \%$ (21/89), borderline reactive in $9 \%(8 / 89)$ and negative in 67\% (60/89) persons. Among the 89 persons, 54 persons had a VLVL $\leq 1,000 \mathrm{IU} / \mathrm{ml}$, with $\mathrm{HCV}$ antigen testing reactive in $20 \%(11 / 54)$, borderline reactive in 
$4 \%(2 / 54)$ and negative in $76 \%(41 / 54)$ of persons. For the 24 persons with a VLVL and cirrhosis, plasma samples were available in 13 persons; HCV antigen testing was reactive in four, borderline reactive in one and negative in eight persons.

The hepatitis $C$ antigen test was reactive in all control samples with viral loads $>3,000-50,000 \mathrm{IU} / \mathrm{ml}$, and negative in those with undetectable viral loads. 


\section{Discussion}

Using real-life data from the SCCS, we could show that the proportion of treatment-naïve persons with a VLVL was low. Overall $5.3 \%$ of persons ever had a $V L V L \leq 3,000 \mathrm{IU} / \mathrm{ml}$, and during shorter time intervals of 2.5 years this proportion dropped to $3.0-4.3 \%$. This is in line with a previous study which showed a prevalence of 3\% VLVL in Switzerland [24] and with the Georgian HCV Elimination Program where the proportion of viral loads $<1,500 \mathrm{IU} / \mathrm{ml}$ was $1.2 \%$ [37]. In other studies, the prevalence of VLVL had been evaluated among persons who were mostly treatment-experienced, rendering their results not applicable to the context of screening. Despite these differences in study design, the frequency of VLVL was often similar. For example, in two studies including persons with a relapse after HCV treatment, a VLVL $\leq 1,000$ $\mathrm{IU} / \mathrm{ml}$ occurred in $4 \%$ [29], and a VLVL $<5,000 \mathrm{IU} / \mathrm{ml}$ in $16 \%$ of persons [15]. In evaluations of blood samples of mostly treatment-experienced persons, a VLVL $<600 \mathrm{IU} / \mathrm{ml}$ occurred in $2 \%$ [1], and a $V L V L<1,000$ in $3.5 \%$ of persons [29].

In our study, some aspects were favorable in persons who had a VLVL. Firstly, while HCV viral load values usually increase with longer follow-up duration $[38,39]$, the percentage of persons with a VLVL remained constant over a period of $>8$ years (Table 1). Second, although spontaneous clearance is rare during chronic infection [7,34], we found that a relatively large proportion of persons spontaneously cleared their HCV infection: among the 72 persons with a viral load determination performed after their first VLVL, eight (11\%) were confirmed and four (5.5\%) were possible viral clearers. Four active IVDU with confirmed or possible viral clearance and a subsequent detectable viral load were probably reinfected. It is possible that more persons cleared the virus among the 61 persons without viral load tests after the VLVL. Interestingly, young age, which was associated with VLVL $\leq 3,000$ and VLVL $\leq 1,000$ in our study, had previously been described as a predictor of spontaneous clearance $[7,8,34]$, and low viral loads have been reported to precede spontaneous clearance $[7,8]$.

Although the prevalence and incidence of cirrhosis were comparable in persons with and without VLVL in our study, a proportion of $18 \%$ (24/133) cirrhosis in persons with VLVL is worrisome; all of these had excessive alcohol consumption or immunosuppression. If population-based screening for HCV is performed 
with an HCV antibody test followed by HCV antigen testing, or with HCV antigen testing alone, the chronic $\mathrm{HCV}$ infection of these persons may be missed. This problem would not occur in the case of etiological screening of an otherwise unexplained liver disease, where persons who are HCV antibody positive would in general undergo diagnostic workup. However, the likelihood and negative consequences of missing a person with VLVL and cirrhosis during a general population-based screening may be reduced for two reasons: First, point-of-care assays for HCV core antigen are in development, and they may have a lower limit of detection compared to the currently available assay [18]. Second, in some persons with a VLVL and cirrhosis, factors other than HCV were likely predominant in the pathogenesis of the cirrhosis. Indeed, some persons spontaneously cleared their HCV after excessive alcohol consumption or after steroid therapy had been stopped. The frequency of alcohol consumption and immunosuppression including HIV coinfection in our study may mirror the HCV epidemic in Switzerland, which is characterized by a large proportion of IVDU (with increased HIV coinfection and potentially increased alcohol consumption) [40], and by an ageing population with age-related comorbidities $[41,42,43]$. The frequency of VLVL and cirrhosis may therefore be different in other settings. We had too few cases with HBV coinfection and only incomplete information on host genetics for meaningful analyses. Similar to previous studies $[17,22-24,27,28]$, we found no difference in the prevalence of VLVL by HCV genotype.

Usually persons with immunosuppression have high HCV viral loads $[13,38,39,44]$. The occurrence of a VLVL in immunosuppressed and HIV coinfected patients is therefore surprising. We have at present no explanations for this counterintuitive observation.

Our study has a number of strengths and limitations. All persons came from the multicentric SCCS, which includes a large number of patients, some followed up for 16 years [32]. Despite its large size, the SCCS only includes about one tenth of the estimated 40,000 HCV-infected persons in Switzerland [41], and persons in the SCCS may be in a more advanced stage of liver disease [32]. Nevertheless, patient characteristics are similar to the national notification data from the Federal Office of Public Health $[32,41,42]$. The high frequency of viral load tests in some persons may have led to a higher probability of detecting a VLVL. 
Indeed, persons with a VLVL had more viral loads recorded than those without. However, the detection of a VLVL did not lead to an increase in testing. For persons with HIV coinfection, the degree of immunosuppression and the effect of antiretroviral treatment could not be taken into account. It was not always clear whether immunosuppressive treatment was still ongoing. The number of deaths was likely underestimated because some of the patients lost to follow-up may have died. Some of the covariates had missing values that reduced the number of people who could be included in the multivariable analysis, but results were similar when we imputed the missing values by multiple imputation. Information on IFNL3/4 polymorphisms was available for too few persons with VLVL to allow for meaningful analyses.

In conclusion, HCV antigen testing has been shown to perform well well in different geographic locations $[16,17,20,21,37]$, but the low sensitivity for VLVL remains problematic. We show that VLVL that might not be detected by antigen testing are low: VLVL occured in $5.3 \%$ of treatment-naïve persons overall, and numbers will likely be lower for screening, which is based on a single test. In addition, some persons with VLVL had favourable disease courses. Since we found VLVL among persons with immunosuppression and liver cirrhosis, the benefit of HCV antigen testing for screening may be limited by the risk of missing patients with severe liver disease. 


\section{Acknowledgements}

We thank Nefti-Eboni Bempong for the editorial assistance. The Swiss Hepatitis C Cohort Study group comprises Francesco Negro, Laurent Kaiser (Geneva); Markus Heim, Hans Hirsch (Basel); Jean-François Dufour, Nasser Semmo (Bern); Darius Moradpour, Vincent Aubert (Lausanne); Hans H. Siegrist (La Chauxde-Fonds); Andreas Cerny, Gladys Martinetti Lucchini (Lugano); Raffaele Malinverni (Neuchâtel); David Semela, Patrick Schmid, Günter Dollenmaier (St. Gallen); Beat Müllhaupt, Elsbeth Probst-Müller (Zürich); Thomas Fabbro, Marielle Rudquist, Pascal Benkert, Constantin Sluka (Basel Clinical Trial Unit).

\section{Disclaimer}

The funders had no role in study design, data collection and analysis, decision to publish, or preparation of the manuscript.

\section{Funding Statement}

This work was supported by Swiss National Science Foundation grants 3347C0-108782/1 and 33CS30148417/1 to the Swiss Hepatitis C Cohort Study and unrestricted grants to the Swiss Hepatitis C Cohort Study Foundation by AbbVie, Bristol Myers Squibb, Gilead, Janssen-Cilag, MSD, Novartis, Roche Pharma Switzerland and Roche Diagnostics. OK is funded by a professorship grant (no 163878) from the Swiss National Science Foundation.

\section{Potential conflicts of interest}

Barbara Bertisch reports grants from Gilead and personal fees from AbbVie and Gilead, outside the submitted work. Francesco Negro reports grants from Gilead and personal fees from AbbVie, Gilead, and MSD, outside the submitted work. Beat Müllhaupt reports grants from Gilead and personal fees from AbbVie, Bayer, BMS, Gilead, and Intercept, outside the submitted work. Patrizia Künzler-Heule reports grants from Janssen, Merck, MSD, and ViiV and personal fees from AbbVie, Norgine, and Sigma-Tau, outside the submitted work. Olivia Keiser reports grants from Gilead, outside the submitted work. 
Matteo Brezzi, Olivier Clerc, Fabio Giudici, Francesco Marinucci, Darius Moradpour, Alberto Moriggia, Cornelia Ottiger, Maroussia Roelens, Patrick Schmid and Cinzia Zehnder have declared no potential conflicts of interest. All authors have submitted the ICMJE Form for Disclosure of Potential Conflicts of Interest. Conflicts that the editors consider relevant to the content of the manuscript have been disclosed. 


\section{References:}

1. Fytili $\mathrm{P}$, Tiemann $\mathrm{C}$, Wang $\mathrm{C}$, et al. Frequency of very low HCV viremia detected by a highly sensitive HCV-RNA assay. J Clin Virol 2007; 39:308-11.

2. Zeuzem S, Franke A, Lee JH, Herrmann G, Ruster B, Roth WK. Phylogenetic analysis of hepatitis C virus isolates and their correlation to viremia, liver function tests, and histology. Hepatol 1996; 24:1003-9.

3. Barreiro P, Labarga P, Fernandez-Montero JV, et al. Rate and predictors of serum HCV-RNA $>6$ million IU/mL in patients with chronic hepatitis C. J Clin Virol 2015; 71:63-6.

4. Pearlman $\mathrm{BL}$, Ehleben $\mathrm{C}$. Hepatitis $\mathrm{C}$ genotype 1 virus with low viral load and rapid virologic response to peginterferon/ribavirin obviates a protease inhibitor. Hepatol 2014; 59:71-7.

5. Hartwell D, Jones J, Baxter L, Shepherd J. Peginterferon alfa and ribavirin for chronic hepatitis C in patients eligible for shortened treatment, re-treatment or in HCV/HIV co-infection: a systematic review and economic evaluation. Health Technol Assess 2011; 15:1-210.

6. Zeuzem S, Buti M, Ferenci P, et al. Efficacy of 24 weeks treatment with peginterferon alfa- $2 b$ plus ribavirin in patients with chronic hepatitis $C$ infected with genotype 1 and low pretreatment viremia. $J$ Hepatol 2006; 44:97-103.

7. Bulteel N, Partha Sarathy P, Forrest E, et al. Factors associated with spontaneous clearance of chronic hepatitis C virus infection. J Hepatol 2016; 65:266-72.

8. Scott JD, McMahon BJ, Bruden D, et al. High Rate of Spontaneous Negativity for Hepatitis C Virus RNA after Establishment of Chronic Infection in Alaska Natives. Clin Infect Dis 2006; 42:945-52.

9. Ijaz B, Ahmad W, Javed FT, et al. Association of laboratory parameters with viral factors in patients with hepatitis C. Virol J 2011; 8:361. 
10. Hisada M, Chatterjee N, Kalaylioglu Z, Battjes RJ, Goedert JJ. Hepatitis C virus load and survival among injection drug users in the United States. Hepatology 2005; 42:1446-52.

11. Adinolfi LE, Utili R, Andreana A, et al. Serum HCV RNA levels correlate with histological liver damage and concur with steatosis in progression of chronic hepatitis C. Dig Dis Sci 2001; 46:1677-83.

12. Shindoh J, Hasegawa K, Matsuyama Y, et al. Low hepatitis C viral load predicts better long-term outcomes in patients undergoing resection of hepatocellular carcinoma irrespective of serologic eradication of hepatitis C virus. J Clin Oncol 2013; 31:766-73.

13. Sullivan DG, Bruden D, Deubner $\mathrm{H}$, et al. Hepatitis $\mathrm{C}$ Virus Dynamics during Natural Infection Are Associated with Long-Term Histological Outcome of Chronic Hepatitis C Disease. J Infect Dis 2007; 196:239-48.

14. Chevaliez S. Virological tools to diagnose and monitor hepatitis C virus infection. Clin Microbiol Infect $2011 ; 17: 116-21$.

15. Hoefs JC, Aulakh VS, Ilagan BJ. Very Low Viral Load (VLVL) Relapse Following Treatment of Naïve Patients with Chronic Hepatitis C. Dig Dis Sci 2012; 57:243-9.

16. Khan H, Hill A, Main J, Brown A, Cooke G. Can Hepatitis C Virus Antigen Testing Replace Ribonucleic Acid Polymerase Chain Reaction Analysis for Detecting Hepatitis C Virus? A Systematic Review. Open Forum Infect Dis 2017; 4:ofw252.

17. Freiman JM, Tran TM, Schumacher SG, et al. Hepatitis C Core Antigen Testing for Diagnosis of Hepatitis C Virus Infection: A Systematic Review and Meta-analysis. Ann Intern Med 2016; 165:34555.

18. Cohn J, Roberts T, Amorosa V, Lemoine M, Hill A. Simplified diagnostic monitoring for hepatitis C, in the new era of direct-acting antiviral treatment. Curr Opin HIV AIDS 2015; 10:369-73. 
19. Rockstroh JK, Feld JJ, Chevaliez S, et al. HCV core antigen as an alternate test to HCV RNA for assessment of virologic responses to all-oral, interferon-free treatment in HCV genotype 1 infected patients. J Virol Methods 2017; 245:14-8.

20. Chakravarti A, Chauhan MS, Dogra G, Banerjee S. Hepatitis C virus core antigen assay: can we think beyond convention in resource limited settings? Braz J Infect Dis 2013; 17:369-74.

21. Duchesne L, Njouom R, Lissock F, et al. HCV Ag quantification as a one-step procedure in diagnosing chronic hepatitis C infection in Cameroon: the ANRS 12336 study. J Int AIDS Soc 2017; 20:21446.

22. Chevaliez S, Soulier A, Poiteau L, Bouvier-Alias M, Pawlotsky J-M. Clinical utility of hepatitis C virus core antigen quantification in patients with chronic hepatitis C. J Clin Virol 2014; 61:145-8.

23. Vanhommerig JW, van de Laar TJW, Koot M, et al. Evaluation of a hepatitis C virus (HCV) antigen assay for routine HCV screening among men who have sex with men infected with HIV. J Virol Methods $2015 ; 213: 147-50$.

24. Ottiger C, Gygli N, Huber AR. Detection limit of architect hepatitis C core antigen assay in correlation with HCV RNA, and renewed confirmation algorithm for reactive anti-HCV samples. J Clin Virol 2013; 58:535-40.

25. Yuksel $\mathrm{P}$, Caliskan R, Ergin $\mathrm{S}$, et al. New approaches to in vitro diagnosis of hepatitis C infection a reason for post transfusion hepatitis: Diagnostic value of determination of hepatitis $C$ virus core antigen. Transfus Apher Sci 2011; 45:247-50.

26. Ross RS, Viazov S, Salloum S, Hilgard P, Gerken G, Roggendorf M. Analytical performance characteristics and clinical utility of a novel assay for total hepatitis $C$ virus core antigen quantification. J Clin Microbiol 2010; 48:1161-8. 
27. Morota K, Fujinami R, Kinukawa $\mathrm{H}$, et al. A new sensitive and automated chemiluminescent microparticle immunoassay for quantitative determination of hepatitis C virus core antigen. J Virol Methods 2009; 157:8-14.

28. Medici MC, Furlini G, Rodella A, et al. Hepatitis C virus core antigen: Analytical performances, correlation with viremia and potential applications of a quantitative, automated immunoassay. J Clin Virol 2011; 51:264-9.

29. Hill A, Roberts T, Amorosa V, et al. Can HCV antigen testing replace HCV RNA PCR analysis, for diagnosis and monitoring of treatment for hepatitis C? American Association for the Study of Liver Disease Conference 2015, San Francisco, Abstract 1826. Hepatology 2015; 62(1, Suppl): 1099A. Available at: https://www.aasld.org/sites/default/files/2015SupplementFULLTEXT.pdf. Accessed 25 Jan 2019.

30. Moscato GA, Giannelli G, Grandi B, et al. Quantitative determination of hepatitis C core antigen in therapy monitoring for chronic hepatitis C. Intervirology 2011; 54:61-5.

31. Ticehurst J, Hamzeh F, Thomas D. Factors affecting serum concentrations of hepatitis C virus (HCV) RNA in HCV genotype 1-infected patients with chronic hepatitis. J Clin Microbiol 2007; 45:2426-33.

32. Prasad L, Spicher VM, Zwahlen M, et al. Cohort Profile: the Swiss Hepatitis C Cohort Study (SCCS). Int J Epidemiol 2007; 36:731-7.

33. Micallef JM, Kaldor JM, Dore GJ. Spontaneous viral clearance following acute hepatitis C infection: a systematic review of longitudinal studies. J Viral Hepat 2006; 13:34-41.

34. Grebely J, Prins $M$, Hellard M, et al. Hepatitis C virus clearance, reinfection, and persistence, with insights from studies of injecting drug users: towards a vaccine. Lancet Infect Dis 2012; 12:408-14.

35. Van Buuren S, Groothuis-Oudshoorn K. MICE: multivariate imputation by chained equations in R. J Stat Softw 2011; 45:1-67. 
36. Sterne J, White I, Carlin J, et al. Multiple imputation for missing data in epidemiological and clinical research: potential and pitfalls. BMJ 2009; 338:b2393.

37. Chitadze N, Sukhiashvili R, Drobeniuc J, et al. Abbott HCV Core Antigen and HCV RNA comparison study in country of Georgia. International Liver Congress 2017, Amsterdam, Poster FRI-199. Available at: https://www.journal-of-hepatology.eu/article/S0168-8278(17)31393-4/pdf. Accessed 25 Jan 2019.

38. Eyster ME, Fried MW, Di Bisceglie AM, Goedert JJ. Increasing hepatitis C virus RNA levels in hemophiliacs: relationship to human immunodeficiency virus infection and liver disease. Multicenter Hemophilia Cohort Study. Blood 1994; 84:1020-3.

39. Fanning L, Kenny-Walsh E, Levis J, et al. Natural fluctuations of hepatitis C viral load in a homogeneous patient population: a prospective study. Hepatol 2000; 31:225-9.

40. Cominetti F, Simonson T, Dubois-Arber F, et al. Analyse der Hepatitis-C-Situation bei den drogenkonsumierenden Personen in der Schweiz. Mandated by the Federal Office of Public Health, Switzerland. 2014;1-182. Available at:

https://www.bag.admin.ch/dam/bag/de/dokumente/mt/forschungsberichte/situationsanalyse-hcvdrogen.download/situationsanalyse-hcv-drogen-de.pdf.situationsanalyse-hcv-drogen. Accessed 25 Jan 2019.

41. Zahnd C, Brezzi M, Bertisch B, Giudici F, Keiser O. Analyse de situation des hépatites B et C en Suisse. Mandated by the Federal Office of Public Health, Switzerland. 2017;1-102. Available at: https://www.bag.admin.ch/bag/de/home/dasbag/publikationen/forschungsberichte/forschungsberichte-uebertragbarekrankheiten/situationsanalyse-hepatitis.html. Accessed 25 Jan 2019.

42. Bertisch B, Giudici F, Negro F, et al. Characteristics of foreign-born persons in the Swiss Hepatitis C Cohort Study: implications for screening recommendations. PLoS One 2016; 11: e0155464. 
43. Richard JP, Schaetti C, Basler S, Mäusezahl M. The epidemiology of hepatitis C in Switzerland: trends in notifications, 1988-2015. Swiss Medical Weekly 2018; 148: w14619.

44. Collier J, Heathcote J. Hepatitis C viral infection in the immunosuppressed patient. Hepatol 1998; 27:2-6. 


\section{Figure Legend}

Figure 1: Flowchart of the patient selection process in the Swiss Hepatitis C Cohort Study (SCCS) 
Figure 1

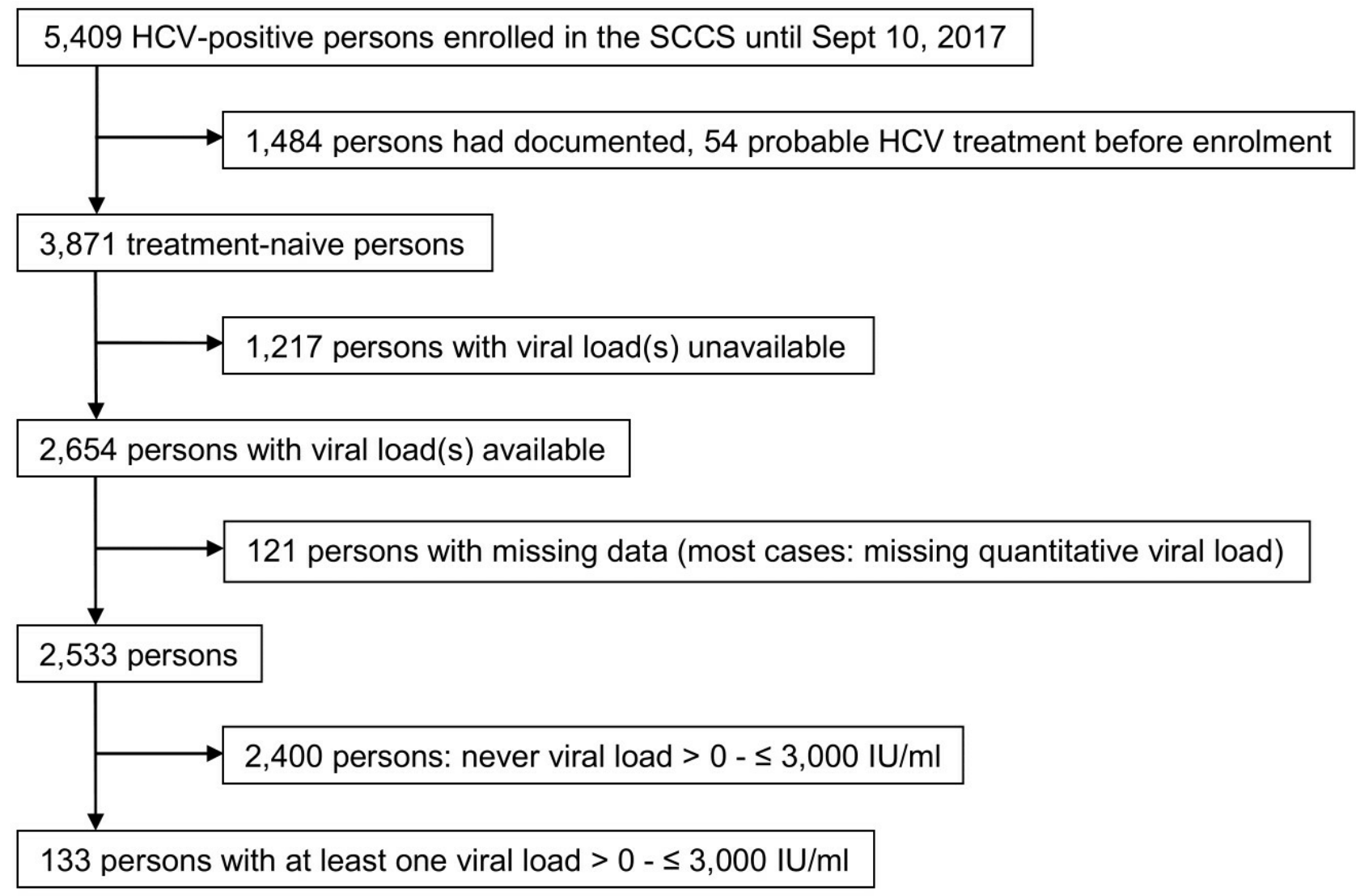


Table 1: Frequency of very low viral loads (VLVL) among persons in the Swiss Hepatitis C Cohort Study

Persons with at least one VLVL value, among all participants with $\geq 1$ HCV RNA value(s)

Total

$133 / 2,533(5.3 \%)$

\begin{tabular}{lc}
\hline Time since enrolment & \\
$<6$ months & $50 / 1,760(2.8 \%)$ \\
$\geq 6$ months to $<3$ years & $37 / 1,237(3.0 \%)$ \\
$\geq 3$ years to $<5,5$ years & $27 / 662(4.1 \%)$ \\
$\geq 5,5$ years to $<8$ years & $17 / 399(4.3 \%)$ \\
$\geq 8$ years & $18 / 442(4.1 \%)$ \\
\hline
\end{tabular}

VLVL $=$ detectable $\mathrm{HCV}$ RNA $\leq 3,000 \mathrm{IU} / \mathrm{ml}$ 
Table 2: Predictors of very low viral loads (VLVL) in the Swiss Hepatitis C Cohort Study

\begin{tabular}{|c|c|c|c|c|c|}
\hline & $\begin{array}{l}\text { No of persons } \\
\quad(N=2,533)\end{array}$ & $\begin{array}{c}\text { Ever } \\
\text { VLVL } \\
(\mathrm{N}=133)\end{array}$ & $\begin{array}{l}\text { Univariable OR } \\
\text { for VLVL }\end{array}$ & $\begin{array}{c}\text { Multivariable } \\
\text { OR for VLVL } \\
(\mathrm{N}=2,166)\end{array}$ & $\begin{array}{c}\text { Multiple } \\
\text { imputation OR }\end{array}$ \\
\hline Gender & & & $(\mathrm{N}=2,532)$ & & \\
\hline Female & 1,016 & 61 & 1 & 1 & 1 \\
\hline Male & 1,516 & 72 & $0.78[0.55 ; 1.11]$ & $0.67[0.45 ; 1.00]$ & $0.72[0.50 ; 1.04]$ \\
\hline Age (years) & & & $(\mathrm{N}=2,527)$ & & \\
\hline $18-\leq 40$ & 1,064 & 71 & 1 & 1 & 1 \\
\hline$\geq 41$ & 1,463 & 62 & $0.62[0.44 ; 0.88]$ & $0.56[0.37 ; 0.85]$ & $0.58[0.40 ; 0.86]$ \\
\hline Genotype & & & $(\mathrm{N}=2,244)$ & & \\
\hline 1 & 1,185 & 61 & 1 & 1 & 1 \\
\hline 2 & 181 & 11 & $1.19[0.62 ; 2.31]$ & $1.33[0.66 ; 2.69]$ & $1.22[0.61 ; 2.45]$ \\
\hline 3 & 604 & 25 & $0.80[0.49 ; 1.28]$ & $0.77[0.47 ; 1.27]$ & $0.76[0.46 ; 1.25]$ \\
\hline 4 & 274 & 18 & $1.30[0.75 ; 2.23]$ & $1.20[0.68 ; 2.12]$ & $1.29[0.74 ; 2.26]$ \\
\hline IVDU & & & $(N=2,508)$ & & \\
\hline No & 972 & 53 & 1 & 1 & 1 \\
\hline Yes & 1,536 & 79 & $0.94[0.66 ; 1.34]$ & $0.70[0.44 ; 1.12]$ & $0.77[0.51 ; 1.18]$ \\
\hline Time (years) & & & $(N=2,485)$ & & \\
\hline $0-2$ & 1,124 & 67 & 1 & 1 & 1 \\
\hline$>2-6$ & 581 & 27 & $0.77[0.49 ; 1.22]$ & $0.74[0.45 ; 1.23]$ & $0.69[0.43 ; 1.11]$ \\
\hline$>6-10$ & 389 & 16 & $0.68[0.39 ; 1.18]$ & $0.75[0.41 ; 1.36]$ & $0.61[0.34 ; 1.08]$ \\
\hline$>10$ & 391 & 19 & $0.81[0.48 ; 1.36]$ & $1.10[0.62 ; 1.95]$ & $0.88[0.52 ; 1.50]$ \\
\hline $\begin{array}{l}\text { Alcohol } \\
\text { consumption }\end{array}$ & & & $(N=2,520)$ & & \\
\hline No or light & 1,323 & 64 & 1 & 1 & 1 \\
\hline Moderate & 398 & 20 & $1.04[0.62 ; 1.74]$ & $1.25[0.71 ; 2.18]$ & $1.18[0.69 ; 1.99]$ \\
\hline Excessive & 633 & 40 & $1.33[0.88 ; 1.99]$ & $1.46[0.89 ; 2.38]$ & $1.48[0.95 ; 2.31]$ \\
\hline Former excess. & 166 & 9 & $1.13[0.55 ; 2.31]$ & $0.85[0.33 ; 2.21]$ & $1.32[0.62 ; 2.77]$ \\
\hline HIV coinfection & & & $(N=2,533)$ & & \\
\hline Yes & 212 & 20 & 1 & 1 & 1 \\
\hline No & 2,321 & 113 & $0.49[0.30 ; 0.81]$ & $0.45[0.25 ; 0.81]$ & $0.47[0.28 ; 0.81]$ \\
\hline HBV coinfection & & & $(\mathrm{N}=2,533)$ & & \\
\hline Yes & 47 & 5 & 1 & & 1 \\
\hline No & 2,486 & 128 & $0.46[0.18 ; 1.17]$ & $0.94[0.22 ; 4.06]$ & $0.50[0.19 ; 1.33]$ \\
\hline Cirrhosis & & & $(N=2,506)$ & & \\
\hline Yes & 236 & 13 & 1 & & 1 \\
\hline No & 2,270 & 119 & $0.95[0.53 ; 1.71]$ & $0.99[0.48 ; 2.06]$ & $0.87[0.47 ; 1.63]$ \\
\hline
\end{tabular}


$\mathrm{VLVL}=$ detectable $\mathrm{HCV} R N A \leq 3,000 \mathrm{IU} / \mathrm{ml}$. IVDU = (history of) intravenous drug use. Time (years) = time elapsed between first documentation of HCV infection and enrollment. Alcohol consumption: no or light: 0$<20$ grams of alcohol per day, moderate: $20-40$, excessive: $>40$, former: $>40$ before enrolment. Numbers do not always sum up to the total number of persons, due to missing values in covariates. Odds ratios (OR) with $95 \%$ confidence intervals, based on logistic regression. 
Table 3: Cirrhosis at enrolment, incident cirrhosis and mortality in persons with compared to persons without a very low viral load value, in the Swiss Hepatitis C Cohort Study

Univariable Multivariable*

\begin{tabular}{lll}
\hline Cirrhosis at enrolment & OR $0.95[0.53 ; 1.71]$ & OR $0.99[0.47 ; 2.08]$ \\
\hline Incident cirrhosis & HR $0.77[0.38 ; 1.56]$ & HR $0.63[0.28 ; 1.44]$ \\
\hline Mortality & HR $0.73[0.39 ; 1.37]$ & HR $0.46[0.20 ; 1.06]$ \\
\hline
\end{tabular}

Very low viral load = detectable HCV RNA $\leq 3,000 \mathrm{IU} / \mathrm{ml}$.

OR: odds ratio from logistic regression; HR: hazard ratio from Cox regression.

* The inclusion of covariates is explained in the methods section. 